africanus and Sahelanthropus tchadensis). Such reactions say less about the facts than the mindsets of commentators, who might be unwilling to have their comfortable views of the world so forcibly changed. Confronted with what might be a genuine unicorn, many would prefer to see a pantomime horse with a spike glued to its head.

After that, research fades into hypothesis, and thence into myth. It was perhaps inescapable that the researchers chose to name their find 'hobbit', after those small, secretive and entirely fictitious residents of J. R. R. Tolkien's Middleearth. It may be telling that the researchers couldn't even agree on this soubriquet, but it was wished upon them by the press.

And what of Homo floresiensis? Although the most parsimonious view is that it is Homo erectus writ small, Morwood reminds us that evolution is not obliged to be parsimonious, and that the very existence of $H$. floresiensis reminds us that much remains undiscovered. In which case, perhaps the researchers were right to begin with in supposing that their creature represented a hitherto unknown and primitive hominid that arrived in southeast Asia, from places unknown, long before Homo evolved.

The unicorn remains as it always did, frustratingly elusive. This year, the researchers will return to Liang Bua to see if they can discover more. But stories such as this demand a mythological beast altogether less serene. It is as if the researchers had set out to discover some new form of fossil mouse, only to find that they had grabbed a dragon by the tail instead. And as any devotee of Harry Potter will remind you: Draco dormiens nunquam titillandus.

Henry Gee is a senior editor of Nature and the author of The Science of Middle-Earth.

\title{
A user's guide to technology
}

\section{The Shock of the Old: Technology in Global History Since 1900 \\ by David Edgerton \\ Profile/Oxford University Press: 2007. \\ 320 pp. $€ 18.99 / \$ 26$}

\section{Andrew Nahum}

As an academic discipline, the history of technology has spent many decades refining models of technological change. There has been a move from a relatively deterministic 'engineering darwinism' to considering technologies, at least in part, as being elicited and selected in the light of social values, aspirations and prejudices.

The polemical thrust of David Edgerton's book The Shock of the Old, however, is that this analysis of the succession of technologies, techniques and machines has the wrong focus. It is hopelessly biased towards innovation and novelty, and implicitly creates a tidy 'timeline of progress'. Moreover, things are not always as they seem. For example, B-52 bombers, an important part of the US Air Force today, are almost 50 years old and might be flown by the grandsons of their first pilots. In the Second World War, more than half-a-million horses dragged the 'mechanized' German army into Russia, while Britain's wooden Mosquito aircraft outpaced metal Messerschmitts.

Counter-intuitive examples such as these are the firecrackers of Edgerton's original and timely book, which has been promoted and packaged on the basis of the title and these oldnew teasers. However, the author does not fully complete this advertised mission, for his real agenda is to promote an analysis of technology that is rooted in use and in practice, rather than in innovation and invention.

"One particularly important feature of usebased history of technology," Edgerton argues, "is that it can be genuinely global." Rather than focusing on the dichotomy between the technology-rich developed world and what Edgerton calls the 'poor world', usually presumed to be deficient in technology or furnished only with second-hand or debased versions, userbased history engages "with all the world's population, which is mostly poor, non-white and half female".

This reading of the dislocation between the present reality and our "reheated futurism" is typified by a section on urban development entitled 'Not Alphaville but bidonville', which notes that by the end of the twentieth century, "most of the largest cities in the world were poor places where once Paris, London and New York led in scale and opulence". Whether built from the oil drums (bidons) of North Africa, or the crates used to import tractors to Durban, these urban centres are home to distinctive, and effective, local 'creole technologies' about which we understand far too little. The book is filled with powerful and thought-provoking examples derived from Edgerton's enormous experience of the mainstream history of technology, but also, unusually, of South America and other parts of the 'poor world'.

With his emphasis on use, the author takes us into areas that most accounts of technology overlook, such as slaughterhouses and execution chambers. In one of the most valuable essays he reminds us that many people (perhaps most?) engage with technology through repair and maintenance. According to this perspective, the technological story of Toyota or Mercedes is not exemplified by the production lines and industrial culture of Nagoya or Stuttgart, emblematic though these may be in technological history. Equally important are the communal repair sites of Ghana known as 'magazines', where tools are rudimentary - "hammers, spanners in incomplete sets, files and screwdrivers" - but where the vehicles are reworked to be indefinitely maintainable, within their local system, and where those who repair them get to know them much more intimately than do drivers or mechanics in any rich country.

The account is a compelling tour de force and a corrective. My own institution, the Science Museum in London, does not entirely escape; he scolds it for an 'innovation timeline' that orders the showcase gallery "grandly" entitled 'Making of the Modern World'. However, as curators, we believe it is most effective to engage with audiences, initially at least, through what they know about technology. We may regret that an older historiography of technology dominates public understanding, but this is the case nonetheless, so icons

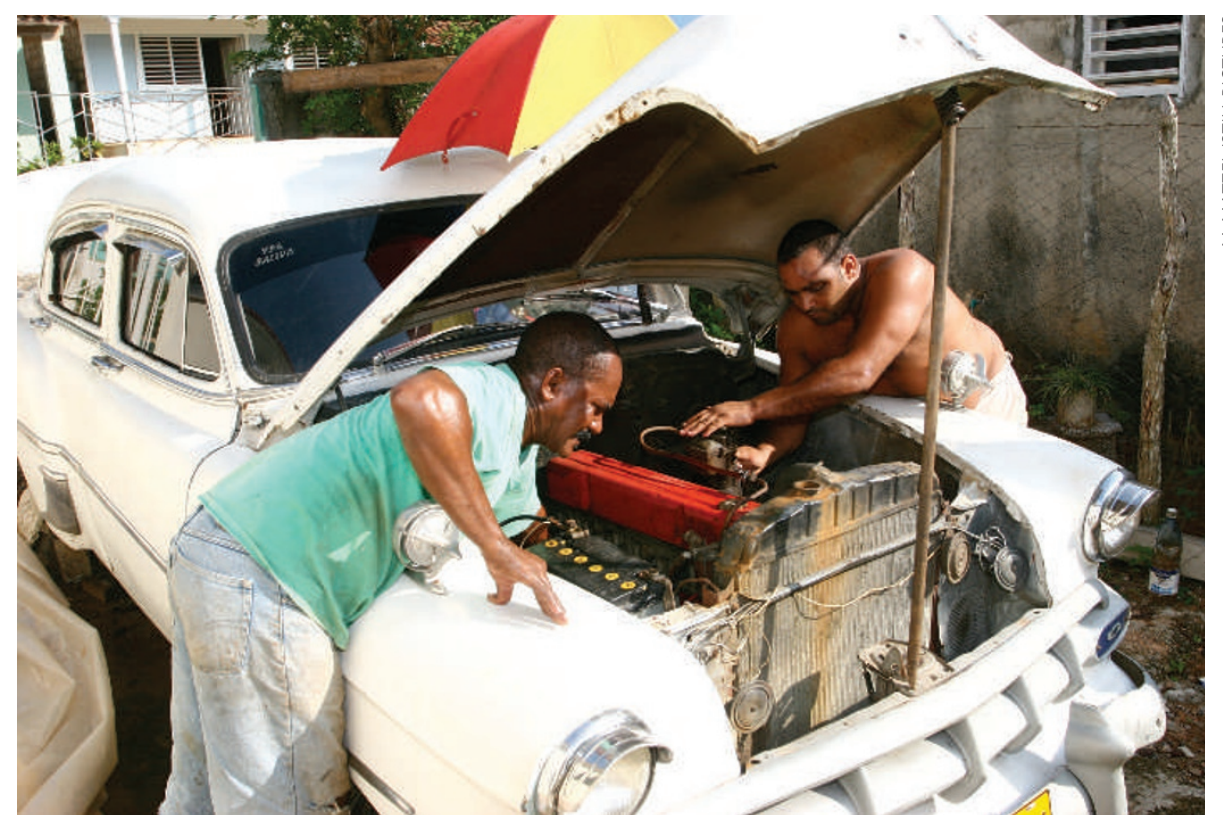

A hands-on approach: mechanics in Cuba maintain old American cars indefinitely using basic tools. 
such as Stephenson's Rocket help us to engage a wide audience. Of course, we also aim to add a deeper and more nuanced understanding, and those who penetrate a little farther into the gallery find an exactly parallel (and very popular) timeline display on the technology of everyday life - familiar and once-familiar artefacts that have earned a presence through use at home, in the workplace and at play.

Icons of invention do exist in our imaginations, but Edgerton seems unprepared to accept that humans navigate their culture by identifying exceptional events and discontinuities. Nor is he concerned with exploring the intriguing mental and cultural processes that make certain inventions or episodes memorable and emblematic. But this is not to deny the great importance, and the interest, of what he has started here.

Ultimately, the pursuit of a more global or democratic history is not unproblematic. What would a use-based history of technology be like, and how would it be more than a natural history? It would not be a replacement for other accounts, perhaps, but one running in parallel.

Finally, there is more to understanding than argument alone, and the author is often most persuasive when he is, perhaps unknowingly, being impressionistic and descriptive. One passage in particular was especially evocative and, almost in itself, seemed to validate the whole historiographic attempt: "Travelling through the poor world it is hard to miss... tiny metal-working shops where the most complex bit of machinery may well be an oxyacetylene, or electric, torch for welding." It is from such shops that "at dusk, bright intermittent light from welding illuminates streets all over the world."

Andrew Nahum is principal curator of technology and engineering at the Science Museum, Exhibition Road, London SW7 2DD, UK.

\section{The fall of a wonder drug}

\section{Penicillin: Triumph and Tragedy \\ by Robert Bud \\ Oxford University Press: 2007. 344 pp. $£ 30, \$ 55$}

\section{Hugh Pennington}

Alexander Fleming discovered penicillin in September 1928. He sent his initial observations to the British Journal of Experimental Pathology on 10 May 1929 and they were published a month later. The paper made little impact. It is very different now, of course. Antiquarian booksellers salivate at the thought of a copy and value it not far short of the price of a first edition of a James Bond book by another Fleming.

The circumstances surrounding the discovery of penicillin have been described many times. Most accounts are celebratory, some hagiographic. The best one, which is neither, is Ronald Hare's The Birth of Penicillin and the Disarming of Microbes (Allen \& Unwin, 1970). Hare was there, in the Inoculation Department of St Mary's Hospital in London, when Fleming made his discovery.

Robert Bud's book Penicillin is the sequel to Fleming's story and is far from celebratory. The development of antibiotic resistance gets more space than tales of therapeutic success; these are the tragedy and triumph of its subtitle. A major theme is penicillin as a brand. Driving the book is the notion that the casting of penicillin as a 'wonder drug' has done more harm than good. The case is persuasive. By the 1950s, penicillin was cheap enough and safe enough to be used freely and on a grand scale by general practitioners and veterinarians, and the perception of its impact caused not only the general public but many medical specialists to imagine they were living in an era that would soon see the end of infectious disease as a public-health problem. Penicillin was given much of the credit for the undoubted decline in infection that had taken place in Europe and North America. But it was the abundantly available clean water for drinking and washing that had seen off cholera, typhoid and typhus.

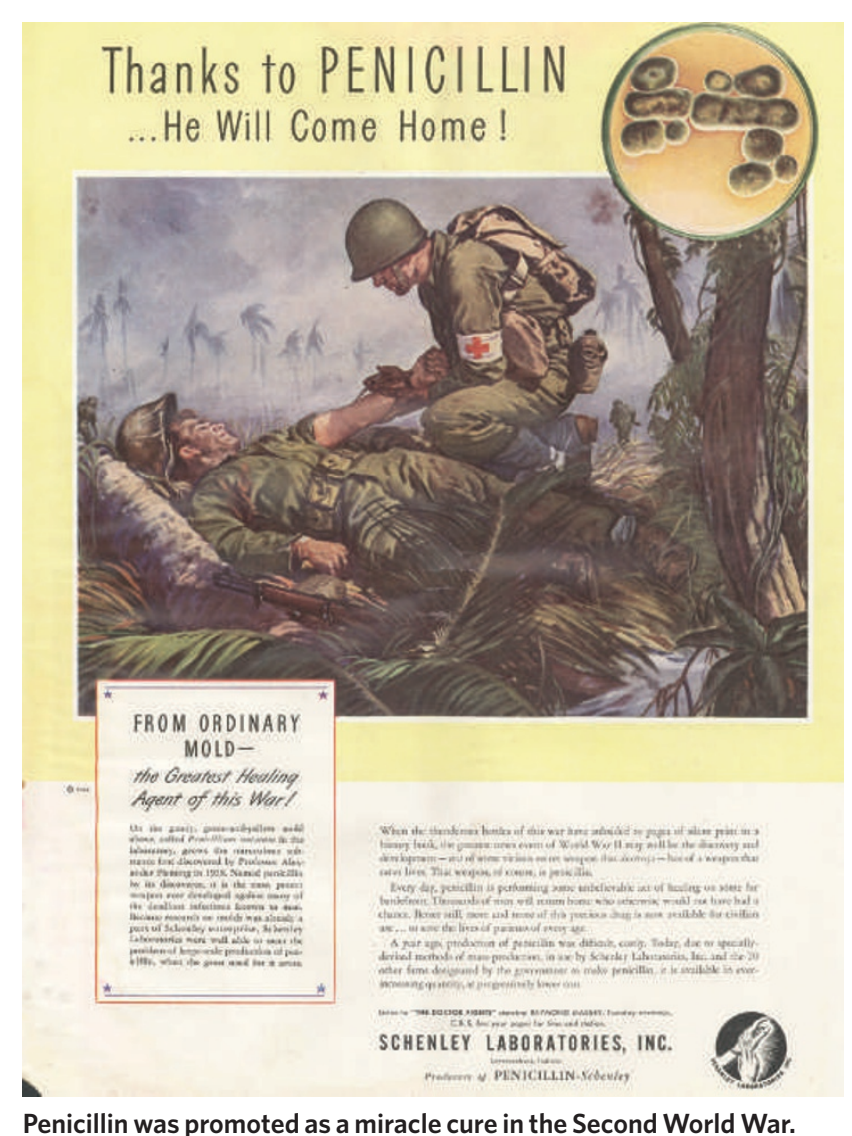

to typify the power of the science that had led to the Anglo-American victory. But he also covers the controversies: how influential politicians, journalists and newspaper owners canonized Fleming, rather than Howard Florey, who led the team that turned penicillin into a drug; and how penicillin joined the Frisch-Peierls memorandum on the manufacture of the atomic bomb and the cavity magnetron as British scientific achievements from which it could be said that the Americans had unreasonably benefited. Bud goes on to recount the development of penicillin derivatives designed to deal with resistant bacteria and public policy responses to the same problem. He ends on a pessimistic note: in essence, the strength of the brand has been outmatched by bacterial evolution.

A focus on the people and institutions involved

Better diet was responsible for the decline in tuberculosis that had been going on for a century. Immunization had made smallpox and diphtheria historical diseases. With the benefit of hindsight we can see that the Streptococcus bacterium that caused scarlet fever - an organism particularly susceptible to penicillin - was becoming less virulent on its own. But of course, from the moment penicillin became generally available, profligate prescription began promoting the spread of resistant pathogens.

Bud shows that the creation of penicillin as a brand owed much to the Second World War and that the strength of its image served
- scientists, policy-makers, propagandists, 'big pharma' and governments - gives a story full of human interest that general readers will enjoy. But this is only the half of it. By and large, the microbes are missing, although in fairness that would have needed another volume. The abiding triumph of penicillin over Treponema pallidum, which turned syphilis from a common scourge to a clinical curiosity, and its difficult relationship with Staphylococcus aureus, which was the organism on Fleming's famous Petri dish and continues today as MRSA, are big stories too.

Hugh Pennington is in the School of Medicine, University of Aberdeen, Aberdeen AB9 2ZD, UK. 